\title{
Regulatory Aspects of Ethanol Fermentation in Immature and Mature Citrus Fruit
}

\author{
Jian Xin Shi', Joseph Riov, Raphael Goren, and Eliezer E. Goldschmidt ${ }^{2}$ \\ The Robert H. Smith Institute of Plant Sciences and Genetics in Agriculture, Faculty of Agricultural, \\ Food and Environmental Quality Sciences, The Hebrew University of Jerusalem, P.O. Box 12, \\ Rehovot 76100, Israel \\ Ron Porat
Department of Postharvest Science of Fresh Produce, Agricultural Research Organization (ARO), the
Volcani Center, P.O. Box 6, Bet-Dagan 50250, Israel
}

AdDitional IndeX words. alcohol dehydrogenase, anaerobic stress, Citrus paradisi, Citrus reticulata, ethylene, pyruvate decarboxylase

\begin{abstract}
Molecular aspects of ethanol fermentation in citrus fruit were investigated in immature and mature 'Star Ruby' grapefruit (Citrus paradisi Macf.) and 'Murcott' mandarin (Citrus reticulata Blanco). Transcript levels of pyruvate decarboxylase (PDC) and alcohol dehydrogenase (ADH), which play a central role in ethanol fermentation, were detectable in all stages of fruit development, but accumulation of acetaldehyde (AA) and ethanol was evident only as fruit approached maturation or after several weeks of storage. Treatment of mature fruit with ethylene enhanced ethanol fermentation in grapefruit but not in mandarin. Immature fruit of both cultivars, on the other hand, responded to ethylene by prominent, although transient, enhancement of ethanol fermentation. Exposure of mature or immature fruit to anaerobic conditions ( $\mathrm{N}_{2}$ atmosphere) upregulated the expression of PDC and ADH, and increased the levels of $\mathrm{AA}$ and ethanol. Exposure of mature fruit to anaerobic conditions also increased the enzymatic activities of PDC and ADH. The data indicate that the potential for ethanol fermentation exists in citrus fruit throughout development, even under aerobic conditions, but AA and ethanol are detected mainly toward maturation or under prolonged storage. However, prominent, long-term molecular induction of ethanol fermentation occurs only under anaerobic conditions imposed by $\mathrm{N}_{2}$ atmosphere.
\end{abstract}

Pyruvate decarboxylase (PDC) and alcohol dehydrogenase (ADH) are two enzymes specifically required for ethanol fermentation. Pyruvate decarboxylase catalyzes the irreversible conversion of pyruvate to acetaldehyde (AA), and ADH subsequently reduces AA into ethanol. In plant tissues, transcript levels of PDC and ADH, and activities of both enzymes increased considerably under low $\mathrm{O}_{2}$ conditions, concomitant with increased production of $\mathrm{AA}$ and ethanol (Ricard et al., 1994). In some plants, however, transcript levels of PDC and ADH, and the respective enzyme activities, increased as well in response to a wide range of other stimuli, such as dehydration, cold, ethylene, abscisic acid, and glucose (Dolferus et al., 1994; Koch et al., 2000; Peng et al., 2001; Tadege and Kuhlemeier, 1997). Increases in AA and ethanol synthesis in response to these stimuli occurred under normoxic $\left(21 \% \mathrm{O}_{2}\right)$ and even under $\mathrm{O}_{2}$-enriched conditions

\footnotetext{
Received for publication 24 July 2006. Accepted for publication 28 Sept. 2006. We thank Prof. Charles L. Guy (University of Florida, USA) and Dr. Avi Sadka (ARO, Israel) for critical review and suggestions on the manuscript. We also thank Ms. Batia Weiss and Mr. Yochanan Zutchi (ARO, Israel) for technical assistance.

${ }^{1}$ Permanent Address: Institute of Farm Product Storage, Shanxi Academy of Agricultural Sciences, Taiyuan 030031, Shanxi, China.

${ }^{2}$ Corresponding author: The Robert H. Smith Institute of Plant Sciences and Genetics in Agriculture, Faculty of Agricultural, Food and Environmental Quality Sciences, The Hebrew University of Jerusalem, PO Box 12, Rehovot 76100, Israel. E-mail: goldsmit@agri.huji.ac.il.
}

(Koch et al., 2000), indicating that ethanol fermentation, an ancient metabolic pathway, functions in plants under both aerobic and anaerobic conditions.

Production of AA and ethanol increased sharply in fruit after postharvest exposure to hypoxic and anoxic conditions, accompanied by an increase in transcript levels of PDC and ADH or activities of both enzymes (Bonghi et al., 1999; Chen and Chase, 1993; Imahori et al., 2000; Ke et al., 1995). In several fruits, however, production of AA and ethanol increased even during on-tree ripening under aerobic conditions (Pesis, 2005), along with an increase in transcript levels of PDC and ADH or activities of both enzymes (Chen and Chase, 1993; Or et al., 2000). Alcohol dehydrogenase transcript levels increased significantly in grape (Vitis vinifera L.) (Or et al., 2000; Tesniere et al., 2004), pear (Pyrus communis L.) (Chervin and Truett, 1999), and tomato (Lycopersicon esculentum Mill.) (Chen and Chase, 1993) after the onset of ripening under normal $\mathrm{O}_{2}$ tension, and in peach [Pyrus persica (L.) Batsch] (Bonghi et al., 1999), sweet pepper (Capsicum annuum L.) (Imahori et al., 2000), and tomato (Chen and Chase, 1993) upon postharvest exposure to hypoxia or anoxia. However, the expression profile of PDC in grape (Tesniere and Verries, 2000 ) or ADH in strawberry (Fragaria Xananassa Duch.) (Moyano et al., 2004) is quite different when considered at the isogene level.

Citrus fruit are generally classified as nonclimacteric, although immature citrus fruit reveal a climacteric-like behavior (Aharoni, 1968; Eaks, 1970; Katz et al., 2004). Citrus fruit produced AA and ethanol even under aerobic 

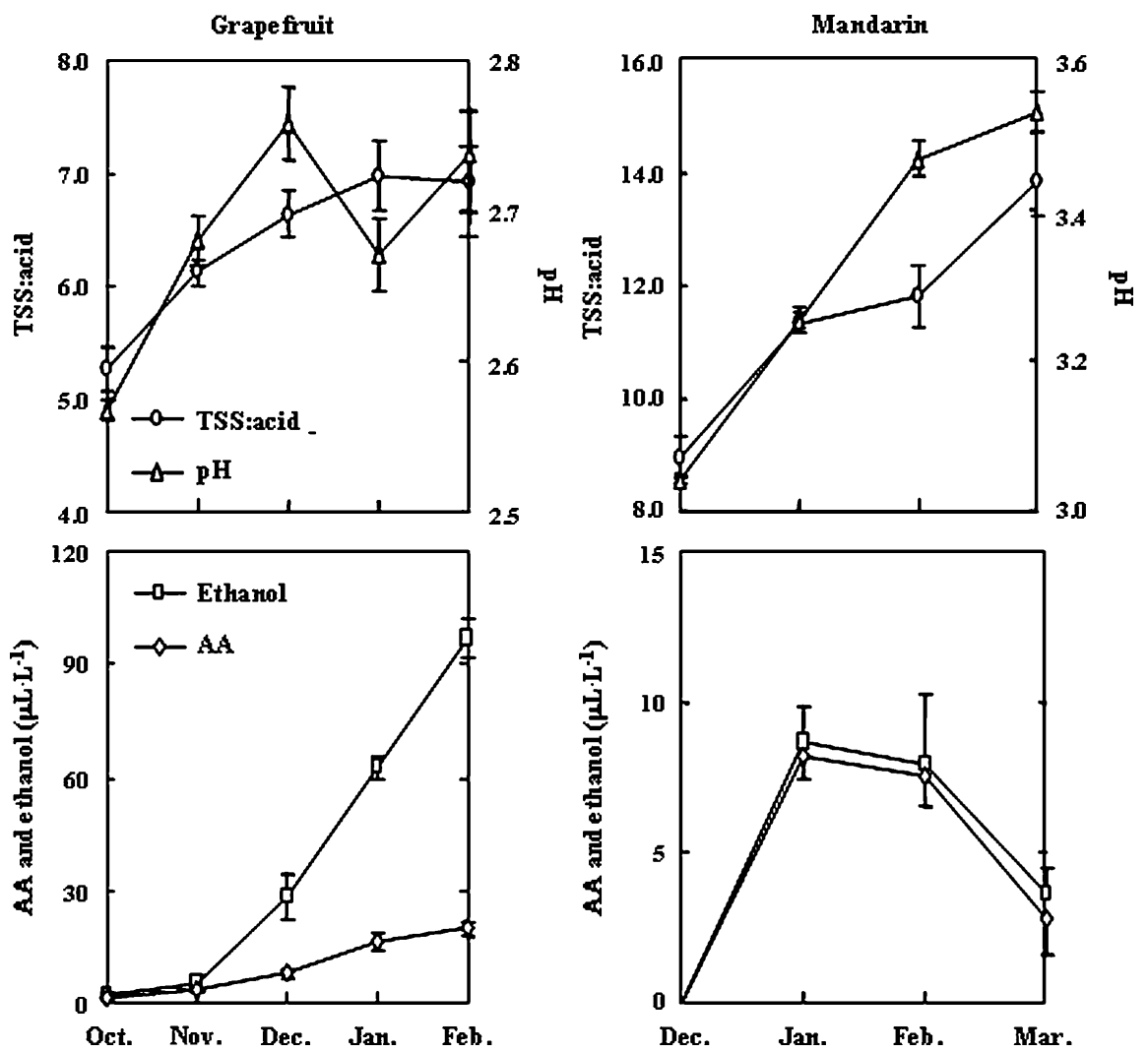

$\mathrm{ADH}$ in the activation of ethanol fermentation in mature and immature citrus fruit, as affected by ethylene and anoxia. The results indicate that although the intensity of ethanol fermentation in citrus fruit is transcriptionally controlled, other, developmental regulatory mechanisms are also apparently involved.

\section{Materials and Methods}

Plant materials and treatments. 'Star Ruby' grapefruit and 'Murcott' mandarin fruit were harvested at stage I (immature fruit) and stage III (mature fruit) of development and were used for the experiments on the day of harvest. $\mathrm{N}_{2}$ treatments were carried out as described previously (Shi et al., 2005b). Mature grapefruit and mandarin fruit were placed together (9 grapefruit and 12 mandarin; total mass, $\approx 4.2 \mathrm{~kg}$ ) into 30 -L air-tight plastic containers, whereas immature grapefruit and mandarin fruit were placed together (total mass, $\approx 400 \mathrm{~g}$ ) into $3.2-\mathrm{L}$ glass jars. Containers or jars were flushed for about $10 \mathrm{~min}$ with pure $\mathrm{N}_{2}$ until the $\mathrm{O}_{2}$ level in the containers or jars was less than $0.5 \%$. The containers or jars were then sealed and kept at $20{ }^{\circ} \mathrm{C}$ for the indicated times. Control fruit were kept in sealed containers or jars at $20{ }^{\circ} \mathrm{C}$ for similar periods. For ethylene treatment, mature and immature fruit were sealed at $20{ }^{\circ} \mathrm{C}$ in the dark in $30-\mathrm{L}$ plastic . Changes in juice total soluble solids (TSS)-to-acid ratio (TSS:acid), pH, AA, and ethano of grapefruit and mandarin during on-tree maturation. Grapefruit and mandarin fruit were harvested and analyzed at the indicated dates (2004-2005 season). Each value represents the average of three measurements at each time point \pm SE. Error bars not shown are smaller than the symbols used. Please note the different scales for grapefruit and mandarin.

conditions during natural, on-tree maturation (Davis, 1971). Postharvest exposure of citrus fruit to hypoxia, anoxia, or wax coating brought about the production of considerable amounts of AA and ethanol (Davis et al., 1973; Norman and Craft, 1971; Shi et al., 2005b). In studies of physiological changes occurring in citrus fruit during storage, off-flavor was found to be associated with elevated concentrations of AA and ethanol in the juice (Cohen et al., 1990; Ke and Kader, 1990; Pesis and Avissar, 1989; Porat et al., 1999). Concentrations of AA and ethanol in the juice of citrus fruit increased also upon exposure to exogenous ethylene (Eaks, 1970; Porat et al., 1999). Some data regarding the regulation of ethanol fermentation in citrus have been provided (Bruemmer, 1986; Davis et al., 1973; Ke and Kader, 1990), but the molecular aspects have not been addressed. The increasing interest in developing anaerobic-based postharvest quarantine treatments to control insect infestations (Ke and Kader, 1990; Shellie, 2002) and the need to reevaluate the behavior of citrus fruit under controlled atmospheres (CAs) (Shi et al., 2005a) prompted us to conduct the current study. The existing evidence suggests that the ethanol fermentation pathway is potentially available in citrus fruit even under normal, aerobic conditions. It attains full metabolic activity, however, only under anaerobic conditions. We hypothesize that this activation involves upregulation of the gene expression of $\mathrm{PDC}$ and $\mathrm{ADH}$.

Thus, the objective of the current study was to examine the involvement of global changes in transcript levels of PDC and containers and 3.2-L glass jars respectively, and fresh ethylene was injected daily after aeration to a final concentration of $10 \mu \mathrm{L} \cdot \mathrm{L}^{-1}$. Similarly, control fruit were sealed and aerated daily without the injection of ethylene. Immediately after treatment, flavedo (outer colored rind) tissues of immature fruit, and both flavedo and juice vesicles (juice sacs with segment membranes) of mature fruit were frozen in liquid nitrogen and stored at $-80^{\circ} \mathrm{C}$ until use.

RESPIRATION AND VOLATILE EVOLUTION RATES. Respiration and volatile evolution rates for mature fruit were measured as described previously (Katz et al., 2004; Shi et al., 2005b). Individual mature fruit were sealed for 2 to $3 \mathrm{~h}$ in nylon bags equipped with syringes closed with rubber serum caps. The air was first gently evacuated from the sealed bags with a vacuum pump for 5 to $10 \mathrm{~s}$ and then $30 \mathrm{~mL}$ fresh air was injected into each bag through the rubber serum cap. The total volumes of the bags including the grapefruit and mandarin inside were $460 \mathrm{~mL}$ and $200 \mathrm{~mL}$ respectively. Individual immature fruit were sealed for $1 \mathrm{~h}$ in $50-\mathrm{mL}$ plastic Falcon tubes capped with serum caps. Gas samples were withdrawn with syringes and injected into a gas chromatograph (GC) for analysis. Carbon dioxide concentration was determined with a Packard 7500 GC (Agilent Technologies, Palo Alto, Calif.) equipped with an Alltech 8700 CTRI packed column (Alltech Associates, Deerfield, Ill.) and a thermal conductivity detector. Acetaldehyde and ethanol concentrations were determined with a Varian 3300GC (Varian, Palo Alto, Calif.) equipped with a Carbowax 20-M column (Sigma-Aldrich Corp., St. Louis, Mo.) and a flame 


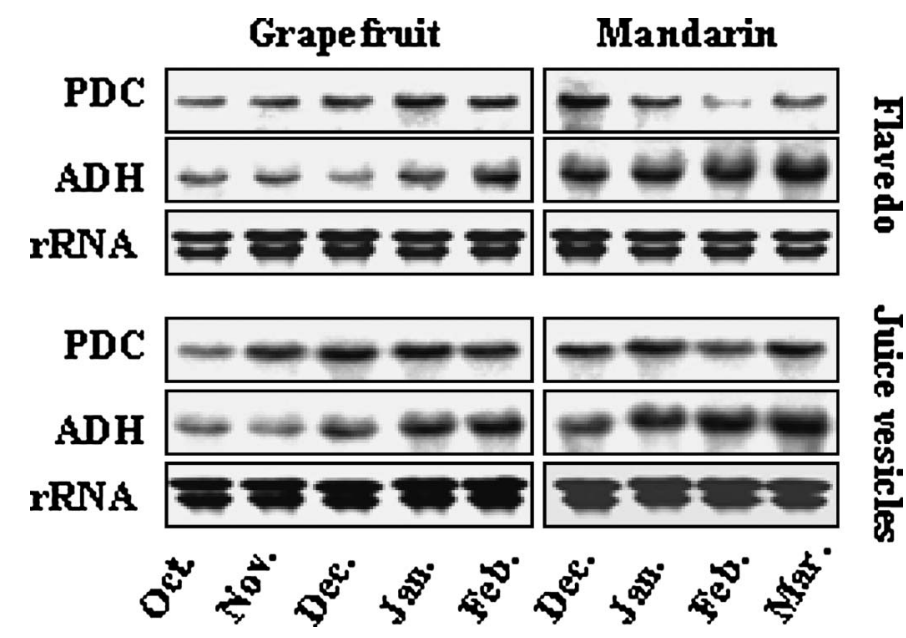

Fig. 2. Change in transcript levels of PDC and ADH of grapefruit and mandarin during on-tree maturation. Grapefruit and mandarin fruit were harvested and analyzed at the indicated dates (2004-2005 season). Total RNA was extracted from flavedo and juice vesicle tissues. Blots were hybridized with specific probes. The ethidium bromide-stained ribosomal RNA (rRNA) bands are shown to indicate the equivalent RNA loading.

ionization detector. In both cases, helium was used as the carrier gas.

Juice volatile, total soluble solids, ACIDity, AND PH. Composite juice was extracted by a hand squeezer from 9 to
12 mature fruit (three to four fruit/measurement). For AA and ethanol volatile determination, $10-\mathrm{mL}$ aliquots were immediately transferred to 50-mL Erlenmeyer flasks sealed with rubber serum caps. The volatiles in the head space were determined with a Varian 3300 GC against known standards, as described previously (Shi et al., 2005b). Total soluble solids was determined with a digital refractometer (Atago Co., Ltd., Tokyo, Japan). Titratable acidity was determined by titration with $0.1 \mathrm{~N} \mathrm{NaOH}$ and calculated as citric acid equivalents. Juice $\mathrm{pH}$ was determined with a multiparameter analyzer (CONSORT, Turnhout, Belgium).

Gene isolation AND SEQuencing. Degenerated primers for $\mathrm{PDC}$ and $\mathrm{ADH}$ were designed based on the conserved domains of homologous genes in the GenBank. Polymerase chain reactions (PCRs) were performed using citrus complementary DNA (cDNA) libraries as templates. Fragments generated from PCR with expected length were cloned into pGEM-T Easy Vector (Promega, Madison, Wisc.) and sequenced. Desirable PDC fragments were obtained from one citrus cDNA library (Jacob-Wilk et al., 1997), and ADH from another citrus cDNA library (Kapri et al., 2000). Isolated genes were submitted to GenBank under the following accession numbers: PDC, DQ083540; ADH, DQ083539.

RNA EXTRACTION AND NORTHERN BLOT ANALYSIS. Total RNA was extracted by a standard sodium dodecyl sulfate (SDS)phenol/chloroform method as described by Ausubel et al. (1995). Twenty micrograms RNA was separated by electrophoresis in $1 \%$ agarose gel containing formaldehyde and blotted onto Hybond-XL nylon membrane (Amersham Biosciences, Buckinghamshire, UK) by capillary transfer.
$\mathbf{A}$
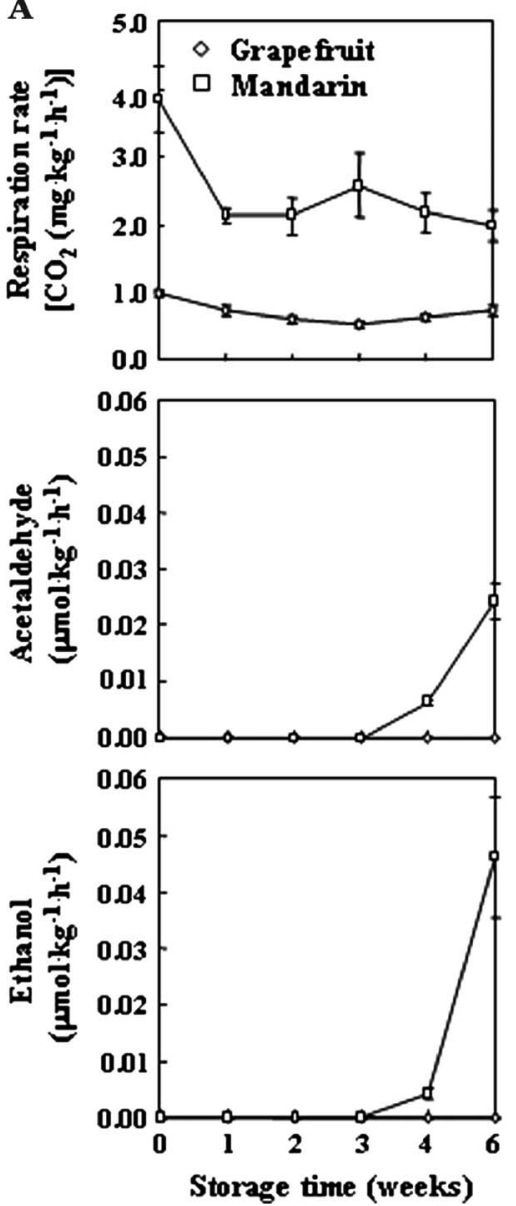

B

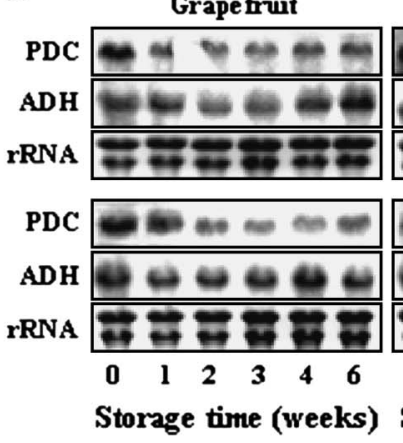

Mandarin
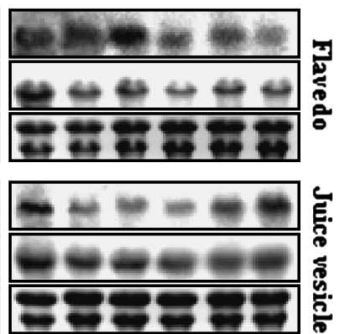

Storage time (weeks)

Fig. 3. Changes in rates of respiration, AA and ethanol evolution, and transcript levels of PDC and ADH in mature grapefruit and mandarin fruit during postharvest storage at $20{ }^{\circ} \mathrm{C}$. Fruit were harvested on $11 \mathrm{Feb}$. 2004. (A) Changes in rates of respiration, AA, and ethanol evolution. Each value represents the average of four individual fruit at each time point \pm SE. Error bars not shown are smaller than the symbols used. (B) Changes in transcript levels of $\mathrm{PDC}$ and $\mathrm{ADH}$ in flavedo and juice vesicles. Total RNA was extracted from flavedo and juice vesicle tissues. Blots were hybridized with specific probes. The ethidium bromide-stained rRNA bands are shown to indicate the equivalent RNA loading.
After electrophoresis, the gel was photographed before blotting to ensure that equal amounts of RNA had been loaded for each example. The RNA blot was hybridized with the specific cDNA probes described earlier and was labeled using a random priming method (Fermentas International, Burlington, Ont., Canada). Hybridization was carried out at $42{ }^{\circ} \mathrm{C}$ in ULTRAhyb hybridization buffer (Ambion, Austin, Texas) for 16 to $20 \mathrm{~h}$ followed by a high-stringency wash. The hybridized membrane was exposed and analyzed by a FLA-5000 phosphorimager (Fuji Photo Film Co., Tokyo, Japan). Generally, two membranes loaded with the same RNAs were used for hybridization in each experiment.

Pyruvate decarboxylase and ALCOHOL DEHYDROGENASE ENZYME EXtraction AND Assay. Pyruvate decarboxylase and ADH enzymes were extracted according to Ke et al. (1995) with the following modifications. Frozen tissue $(3 \mathrm{~g}$ and $8 \mathrm{~g}$ for flavedo and juice vesicles, respectively) was ground to a fine powder 
$\mathbf{A}$
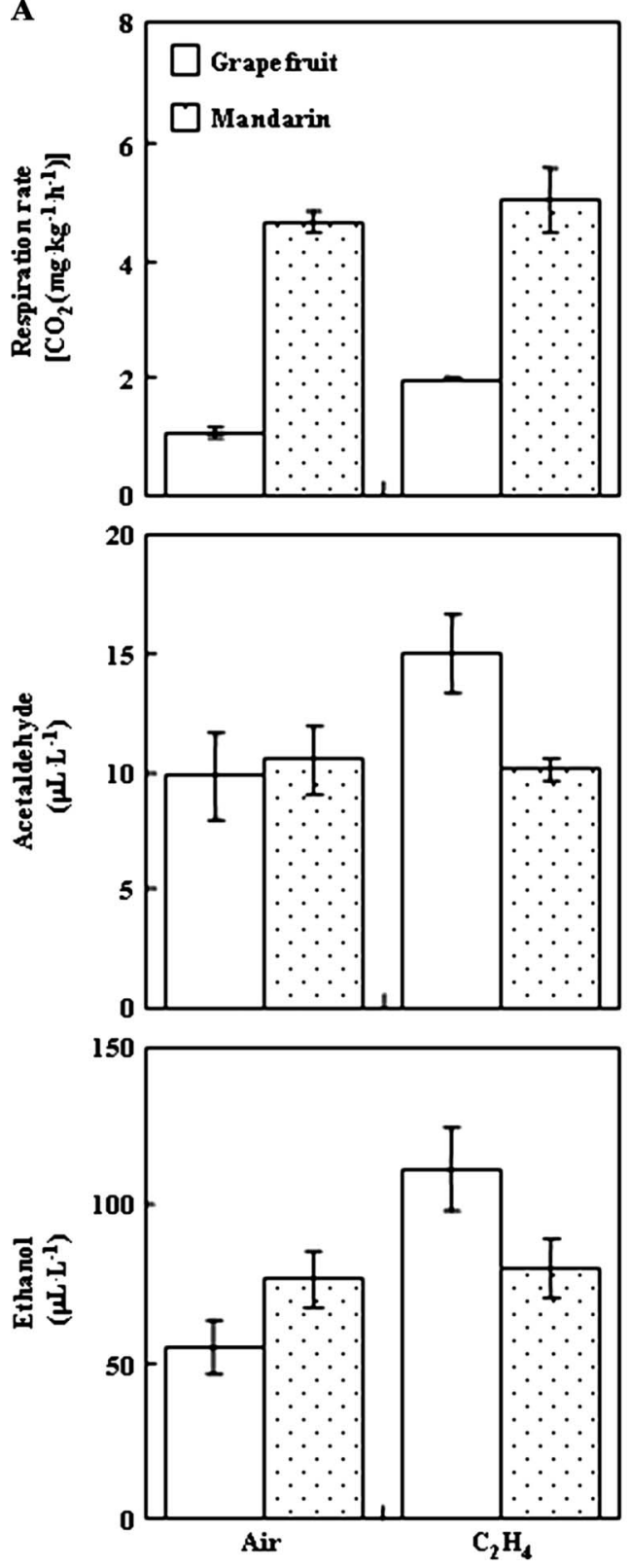

B

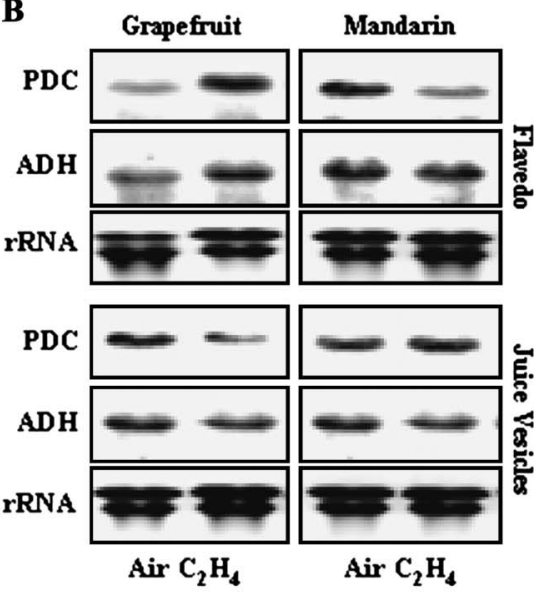

ing to Bradford (1976), using bovine serum albumin as the standard.

\section{Results}

EthaNOL FERMENTATION IN MATURE CITRUS FRUIT. As on-tree maturation advanced, AA and ethanol levels in the juice increased in both cultivars along with increases in the total soluble solidsto-acid ratio and $\mathrm{pH}$ (Fig. 1). However, the actual levels of AA and ethanol varied considerably between these two cultivars; AA and ethanol levels were much lower in mandarin, in the current experiment, and peaked by January. A moderate seasonal increase in transcript levels of PDC and ADH was observed in flavedo and juice vesicles of grapefruit, whereas in mandarin only the transcript level of ADH showed an increase (Fig. 2).

Respiration rates of both cultivars

Fig. 4. Changes in respiration rates of intact fruit, contents of juice AA and ethanol, and transcript levels of PDC and $\mathrm{ADH}$ in mature grapefruit and mandarin after exposure to air (Air) or $10 \mu \mathrm{L} \cdot \mathrm{L}^{-1}$ ethylene $\left(\mathrm{C}_{2} \mathrm{H}_{4}\right)$ at $20{ }^{\circ} \mathrm{C}$ for $24 \mathrm{~h}$. Fruit were harvest on $17 \mathrm{Feb}$. 2004. (A) Changes in respiration rates of intact fruit, contents of juice AA, and ethanol. Each value of respiration rate represents the average of four individual fruit, and each value of juice AA and ethanol level represents the average of three measurements. (B) Changes in transcript levels of PDC and $\mathrm{ADH}$ in flavedo and juice vesicles. Total RNA was extracted from flavedo and juice vesicle tissues. Blots were hybridized with specific probes. The ethidium bromide-stained rRNA bands are shown to indicate the equivalent RNA loading.

in liquid $\mathrm{N}_{2}$, then reground with cold acetone $(30 \mathrm{~mL}$ and $45 \mathrm{~mL}$ for flavedo and juice vesicles, respectively) and incubated at $-20{ }^{\circ} \mathrm{C}$ for $30 \mathrm{~min}$. The homogenate was filtered through Whatman no. 1 filter paper using a vacuum, and the resultant powder was washed four times with cold acetone and dissolved in $7.5 \mathrm{~mL}$ cold $100 \mathrm{~mm}$ 2-( $\mathrm{N}$-morpholino)ethane-sulfonic acid buffer $(\mathrm{Ph}, 6.5)$ containing $0.5 \mathrm{~mm}$ cysteine, $5 \mathrm{~mm}$ dithiothreitol and $1 \%(\mathrm{w} / \mathrm{v})$ polyvinylpyrrolidone. The homogenate was incubated on ice for $15 \mathrm{~min}$ and filtered through two layers of Miracloth (EMD Biosciences, San Diego, Calif.), and centrifuged at $16,266 \mathrm{~g}_{\mathrm{n}}$ for $15 \mathrm{~min}$ at $4{ }^{\circ} \mathrm{C}$. The supernatant was retained as enzyme extract for measuring PDC and ADH activity. Pyruvate decarboxylase and ADH activities were assayed as described by Ke et al. (1995). Activity of PDC was expressed as micromoles of AA formed/minute/milligram protein, and activity of ADH was expressed as micromoles of reduced form of nicotinamide adenine dinucleotide (NADH) oxidized/minute/milligram protein. Protein was assayed accord- declined during the initial period of postharvest storage at $20^{\circ} \mathrm{C}$. Evolution of AA and ethanol became apparent in mandarin after 3 weeks of storage and increased sharply thereafter, whereas grapefruit did not evolve significant amounts of AA and ethanol during the same storage period (Fig. 3A). Similarly, juice AA and ethanol increased significantly only in mandarin and not in grapefruit during storage (data not shown). Transcript levels of PDC and $\mathrm{ADH}$ in flavedo and juice vesicles declined slightly during the first 3 weeks of storage but recovered thereafter (Fig. 3B).

Treatment of mature fruit with ethylene resulted in moderate increases in respiration rates and $\mathrm{AA}$ and ethanol accumulation in grapefruit but not in mandarin (Fig. 4A). Correspondingly, transcript levels of PDC and ADH increased in response to ethylene only in the flavedo of grapefruit (Fig. 4B). Ethylene had little effect on transcript levels of PDC and $\mathrm{ADH}$ in juice vesicles of both cultivars.

Following exposure to $\mathrm{N}_{2}$ atmosphere, respiration rates and evolution of AA and ethanol (as determined upon their return from $\mathrm{N}_{2}$ atmosphere to air) increased markedly in both cultivars. The longer the exposure to $\mathrm{N}_{2}$ atmosphere, the higher the increases in respiration rates and evolution of AA and ethanol (Fig. 5A). This burst of respiration appears to be a homeostatic response to the anaerobiosis that prevailed while the fruit were under $\mathrm{N}_{2}$ atmosphere. Respiration rates and evolution of AA and ethanol were much higher in mandarin than in grapefruit (Fig. 5A). Transcript levels of PDC and ADH increased markedly in flavedo and juice vesicles of both cultivars even after a short (6-h) exposure to $\mathrm{N}_{2}$ (Fig. 5B). 
$\mathbf{A}$
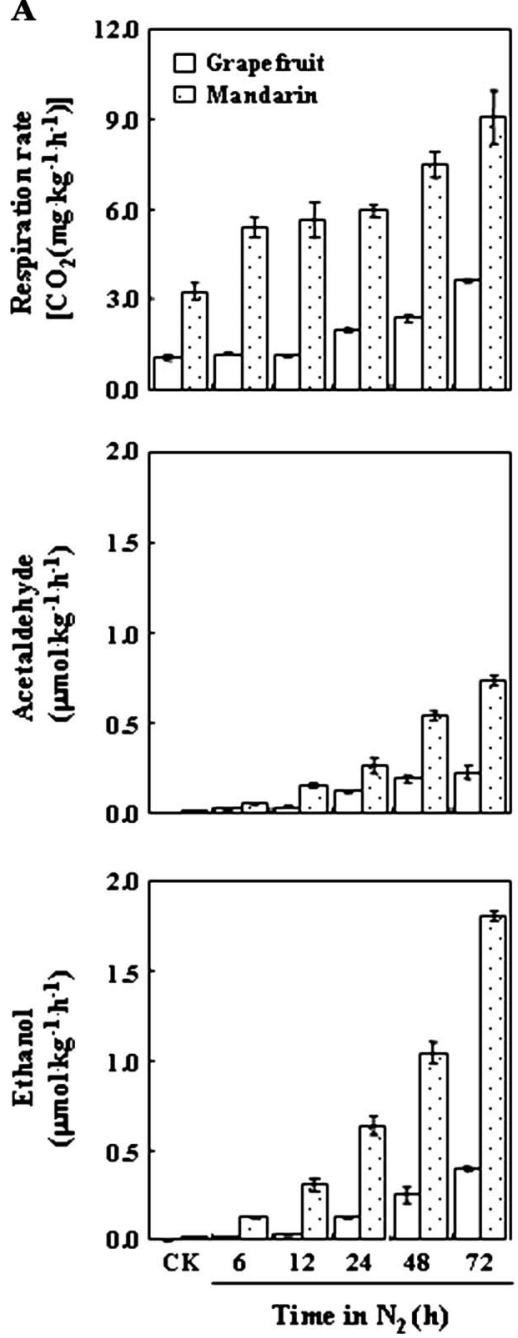

B

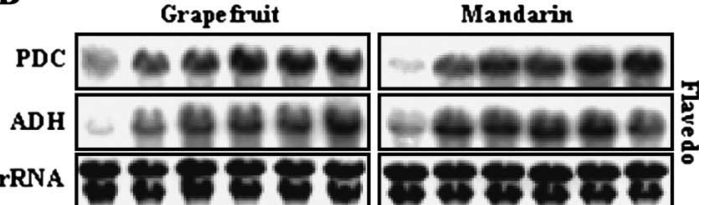

PD

rRNa

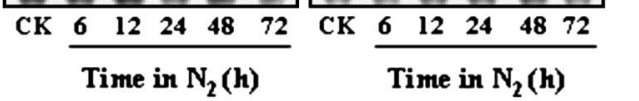

after harvest, then declined gradually during subsequent storage (Fig. 7B).

Treatment of immature fruit with ethylene resulted in a steeper initial reduction in respiration rate, which recovered on day 2 and eventually stabilized at a slightly higher level than the control (Fig. 7A). Exogenous ethylene treatment resulted in a transient burst of AA and ethanol evolution on day 1 , which declined to control levels on day 2 (Fig. 7A). Ethylene brought about a marked increase in transcript levels of PDC and $\mathrm{ADH}$ on day 1 , but transcript levels declined subsequently (Fig. 7B).

Exposure of immature citrus fruit to $\mathrm{N}_{2}$ atmosphere resulted in a decrease in respiration rates and a dramatic increase in $\mathrm{AA}$ and ethanol evolution (Fig. 8A), as determined immediately upon their transfer from $\mathrm{N}_{2}$ atmosphere to air. Acetaldehyde and ethanol evolution of immature mandarin fruit were about two fold higher than that of immature grapefruit. Transcript levels of PDC and $\mathrm{ADH}$ in flavedo of both cultivars increased strongly upon exposure to $\mathrm{N}_{2}$ atmosphere for $6 \mathrm{~h}$ (Fig. 8B). Exposure of immature fruit to $\mathrm{N}_{2}$ atmosphere for $24 \mathrm{~h}$ caused severe peel injury in both cultivars and the flavedo turned dark, thereby preventing RNA analysis.

Upon transfer of fruit from $\mathrm{N}_{2}$ atmosphere to air, there was a period of recovery from the anaerobic stress. Respiration rates declined quickly to control levels but AA and ethanol evolution increased further up to $6 \mathrm{~h}$ after the transfer, and only then declined gradually (Fig. 6A). Transcript levels of PDC in flavedo and juice vesicles of both cultivars declined rapidly after transferring, whereas those of $\mathrm{ADH}$ showed variable trends (Fig. 6B).

Enzyme activities were also examined to determine whether the $\mathrm{N}_{2}$-induced upregulation of PDC and ADH gene expression also affected the respective enzymes. Indeed, PDC activity and, to a lesser extent, ADH activity increased in response to $\mathrm{N}_{2}$ atmosphere in flavedo and juice vesicles of both cultivars (Table 1).

ETHANOL FERMENTATION IN IMMATURE CITRUS FRUIT. Respiration rates of immature fruit were relatively high at harvest $\left(\mathrm{CO}_{2}\right.$ at $302 \mathrm{mg} \cdot \mathrm{kg}^{-1} \cdot \mathrm{h}^{-1}$ and $424 \mathrm{mg} \cdot \mathrm{kg}^{-1} \cdot \mathrm{h}^{-1}$ at $20{ }^{\circ} \mathrm{C}$ for grapefruit and mandarin, respectively), but declined during the first $2 \mathrm{~d}$ and then were rather stable during the following $9 \mathrm{~d}$ of storage. Both immature fruit started to produce small amounts of ethanol, but not AA, from day 1 after harvest (Fig. 7A). Transcript levels of PDC and ADH were low, but nevertheless detectable in flavedo of both cultivars immediately

\section{Discussion}

Transcript levels of the ethanol fermentative genes PDC and $\mathrm{ADH}$ were detectable in citrus fruit throughout development (Figs. 2, 7B and 8B), even when AA and ethanol production were almost undetectable (Fig. 7A). Pyruvate decarboxylase and $\mathrm{ADH}$ expression were upregulated to some extent during the course of on-tree maturation (Fig. 2). This increase in transcript levels of PDC and ADH during citrus maturation did not seem to result from any cue of anaerobiosis, because we did not find any changes in the internal $\mathrm{O}_{2}$ levels of fruit harvested at different maturation stages (data not shown). Furthermore, the expression of PDC and ADH was not confined to internal fruit tissues (juice vesicles) but was apparent even in external peel tissues (flavedo), indicating that ethanol fermentation was not induced in this case by hypoxic conditions. There appears to be a developmental control that potentiates ethanol fermentation in mature fruit even under aerobic conditions.

Expression of PDC and ADH was reported to increase toward ripening in other fruit (Chen and Chase, 1993; Moyano et al., 2004; Or et al., 2000); however, the signal molecule is not known. In the current study we observed an increase in juice $\mathrm{pH}$ during maturation (Fig. 1). Changes in juice $\mathrm{pH}$ may alter 
$\mathbf{A}$
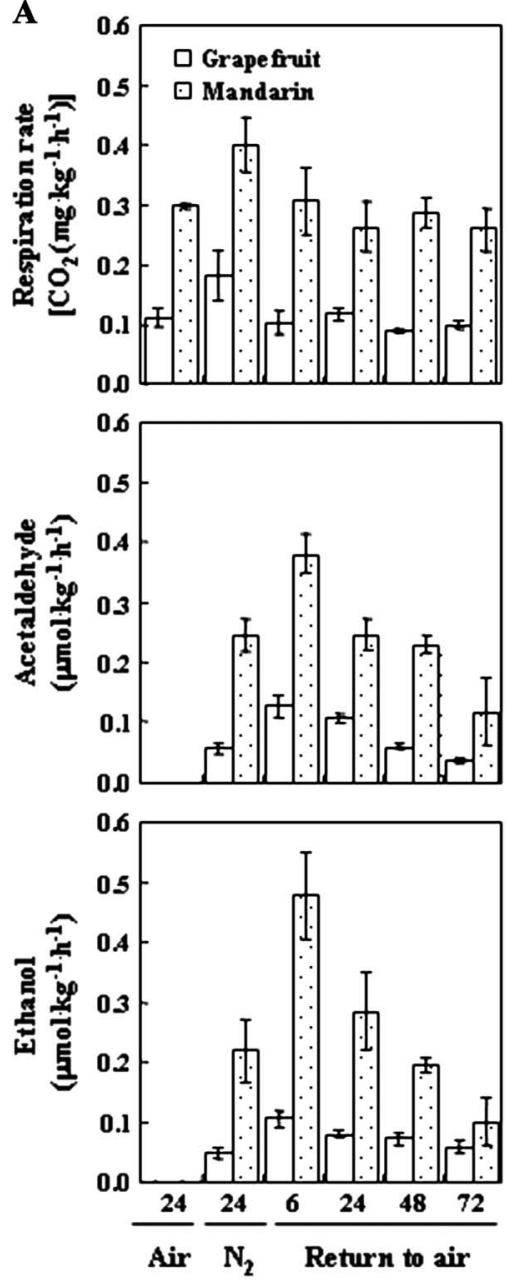

B

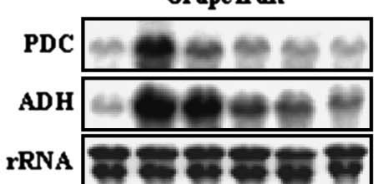

PDC
ADH
rRNA

rRNA
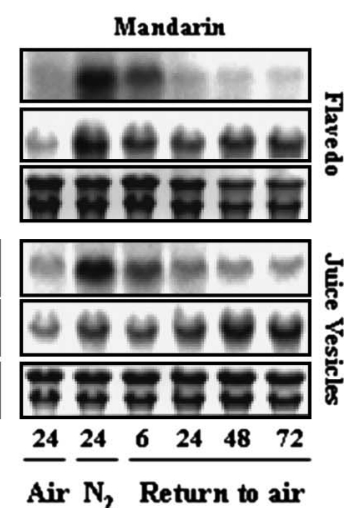

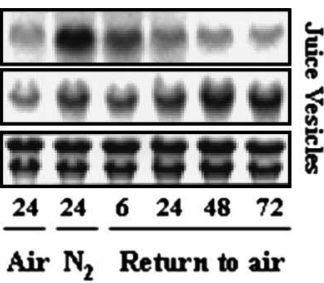

Fig. 6. Changes in rates of respiration, AA and ethanol evolution, and transcript levels of PDC and ADH in mature grapefruit and mandarin fruit during exposure to air or $\mathrm{N}_{2}$ atmosphere for $24 \mathrm{~h}$ and subsequent recovery in air (Return to air). Fruit were harvest on 23 Jan. 2004. (A) Changes in rates of respiration, AA, and ethanol evolution. Each value represents the average of four individual fruit at each time point \pm SE. Error bars not shown are smaller than the symbols used. (B) Changes in transcript levels of PDC and ADH in flavedo and juice vesicles. Total RNA was extracted from flavedo and juice vesicle tissues. Blots were hybridized with specific probes. The ethidium bromide-stained rRNA bands are shown to indicate the equivalent RNA loading.

(Figs. 5B and 6B) and immature fruit (Fig. 8B), and in immature fruit in response to ethylene (Fig. 7B). The physiological and molecular responses of mature citrus fruit to ethylene were rather limited, as expected for citrus, a nonclimacteric fruit (Eaks, 1970). Although grapefruit showed some responses (in rates of respiration, AA and ethanol evolution, and transcript levels of PDC and ADH; Fig. 4), mandarin fruit did not respond, perhaps reflecting their advanced ripening stage.

Immature citrus fruit, which have a climacteric-like behavior (Aharoni, 1968; Eaks, 1970; Katz et al., 2004), responded to ethylene by an abrupt upregulation of PDC and ADH expression, accompanied by a burst of volatile evolution, both of which were, however, transient (Fig. 7B).

Anaerobiosis, imposed by anoxia, remains as the main condition that enhances and accentuates all aspects of ethanol fermentation, from gene expression through enzyme activity down to AA and ethanol production. Some correlation between the changes in gene expression and volatile evolution were also observed in the seasonal trends (Figs. 1 and 2) and the effect of ethylene on mature grapefruit (Fig. 6), but these changes were relatively moderate and do not reflect a real shift to anaerobic metabolism.

the in vivo activity of a number of respiratory enzymes (Nanos and Kader, 1993) or may serve as a signal for the induction of ethanol fermentation (Robert et al., 1989). The function of ethanol fermentation in citrus during natural maturation is not known; but, because AA and ethanol are precursors of natural aroma compounds (Keen and Hatfield, 1981), ethanol fermentation might be involved in the development of aroma volatiles in citrus fruit, as found in other fruits (Lavilla et al., 2001; Moyano et al., 2004).

Prominent changes in PDC and ADH gene expression occurred only upon exposure to $\mathrm{N}_{2}$ atmosphere in both mature
In conclusion, although the molecular and metabolic ethanol fermentation pathway operates at a minimum, basal level throughout citrus fruit development, it becomes more active as fruit approaches maturation and senescence. This includes partial activation by ethylene, which is a universal ripening and senescence signal. Beyond this developmental control, the ethanol fermentation pathway attains maximum activity under anaerobic conditions. Our data demonstrate the role of PDC and ADH gene expression in this metabolic shift, in full support of our working hypothesis.

Table 1. Enzymatic activities of pyruvate decarboxylase (PDC) and alcohol dehydrogenase (ADH) in flavedo and juice vesicle tissues of grapefruit and mandarin kept in air or $\mathrm{N}_{2}$ atmosphere for $24 \mathrm{~h}$ at $20^{\circ} \mathrm{C}$.

\begin{tabular}{|c|c|c|c|c|}
\hline \multirow[b]{2}{*}{ Enzyme activity ${ }^{z}$} & \multicolumn{2}{|c|}{ Grapefruit } & \multicolumn{2}{|c|}{ Mandarin } \\
\hline & Air & $\mathrm{N}_{2}$ & Air & $\mathrm{N}_{2}$ \\
\hline Flavedo PDC & $5.07 \pm 0.91$ & $13.37 \pm 1.67$ & $4.39 \pm 0.47$ & $8.15 \pm 0.45$ \\
\hline Flavedo ADH & $0.41 \pm 0.02$ & $0.73 \pm 0.03$ & $0.54 \pm 0.01$ & $0.63 \pm 0.04$ \\
\hline Juice vesicles PDC & $20.78 \pm 2.81$ & $36.63 \pm 2.21$ & $19.85 \pm 1.77$ & $26.61 \pm 2.56$ \\
\hline Juice vesicles ADH & $0.13 \pm 0.02$ & $0.15 \pm 0.02$ & $0.51 \pm 0.02$ & $0.59 \pm 0.01$ \\
\hline
\end{tabular}

${ }^{\mathrm{z}}$ Results are means of six measurements from two separate experiments \pm SE. Pyruvate decarboxylase (PDC) activity unit: micromoles acetaldehyde (ADH) formed/minute/milligram protein; ADH activity unit: micromoles reduced form of nicotinamide adenine dinucleotide (NADH) oxidized/minute/ milligram protein. 
$\mathbf{A}$
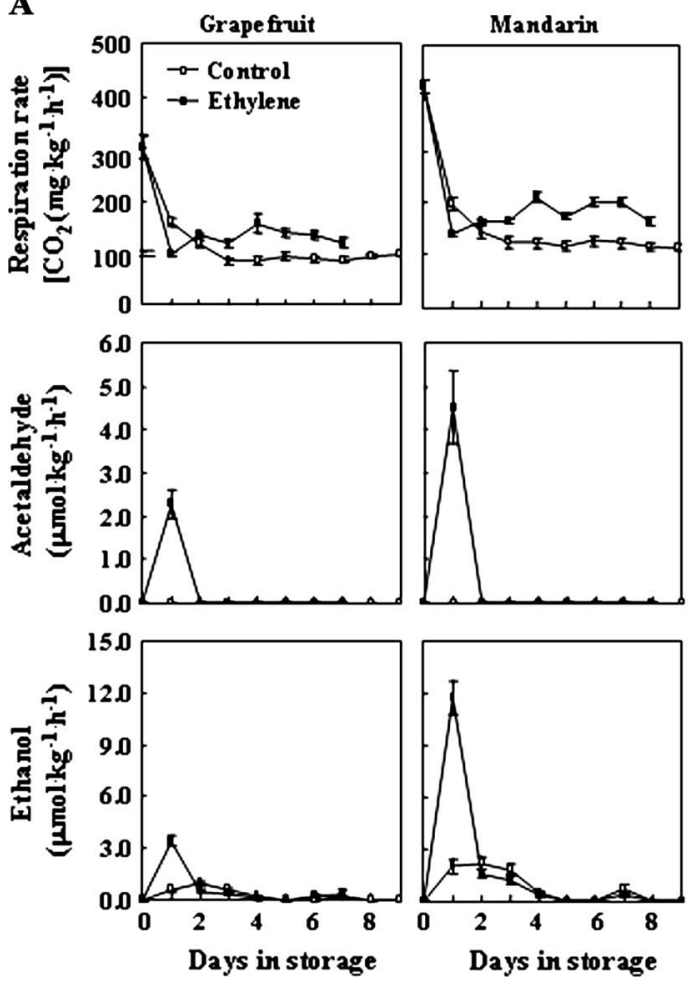

A
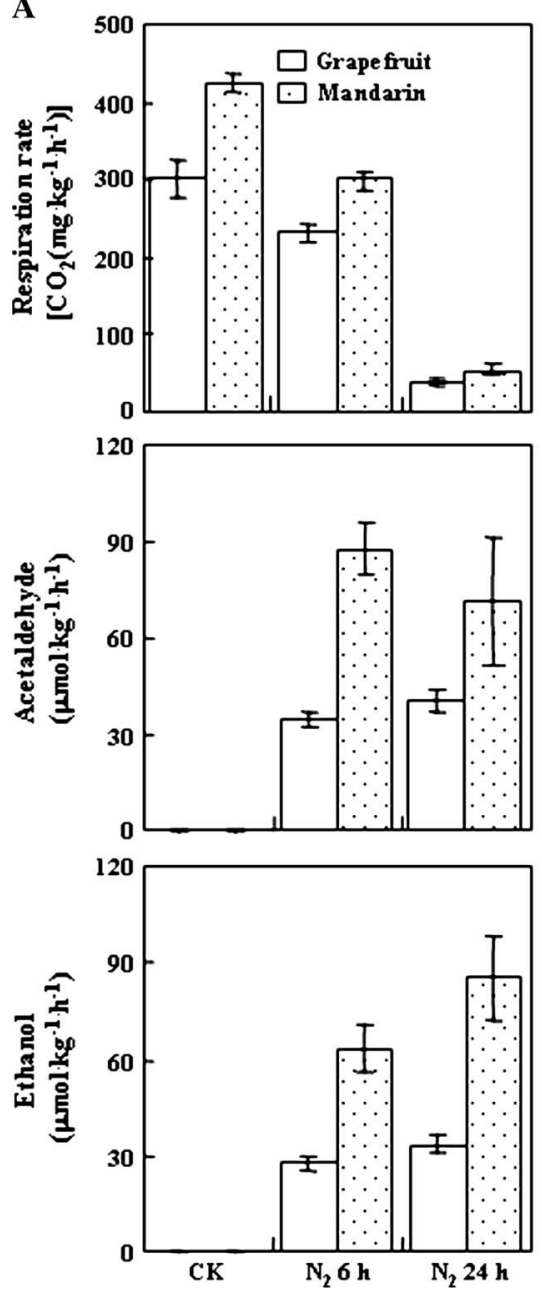

B

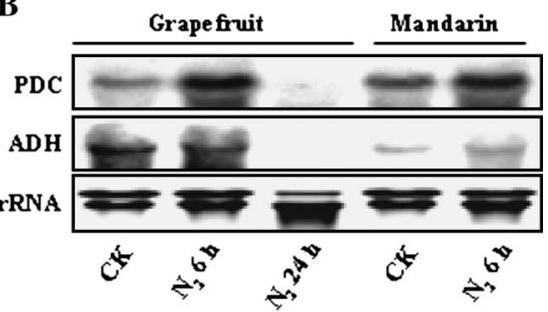

B

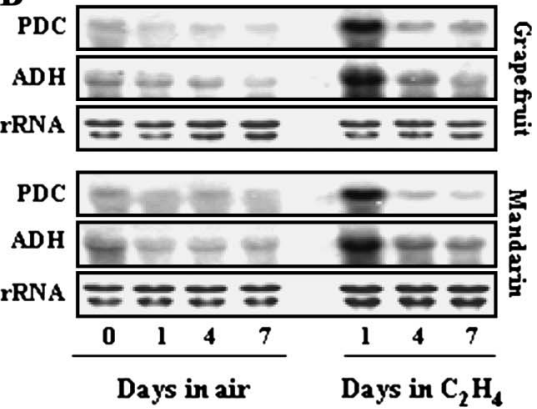

Fig. 7. Changes in rates of respiration, AA and ethanol evolution, and transcript levels of PDC and ADH in immature grapefruit and mandarin. Immature fruit were harvested (16 May 2005) and stored in air (Control) or $10 \mu \mathrm{L} \cdot \mathrm{L}^{-1}$ ethylene at $20^{\circ} \mathrm{C}$ in the dark. (A) Changes in rates of respiration, AA, and ethanol evolution. Each value immature fruit at each time point \pm SE. Error bars not shown are smaller than the symbols used. (B) Changes in transcript levels of PDC and ADH in flavedo. Total RNA was extracted from flavedo. Blots were hybridized with specific probes. The ethidium bromide-stained rRNA bands are shown to indicate the equivalent RNA loading. represents the average of 10 individual

\section{Literature Cited}

Aharoni, Y. 1968. Respiration of oranges and grapefruit harvested at different stages of development. Plant Physiol. 43:99-102.

Ausubel, F.M., R. Brent, R.E. Kingston, D.D. Moore, J.G. Seidman, J.A. Smith, and K. Struhl. 1995. Current protocols in molecular biology. 3rd ed. Wiley, New York.

Bonghi, C., A. Ramina, B. Ruperti, R. Vidrih, and P. Tonutti. 1999. Peach fruit ripening and quality in relation to picking time, and hypoxic and high $\mathrm{CO}_{2}$ short-term postharvest treatments. Postharvest Biol. Technol. 16:213-222.

Bradford, M.M. 1976. A rapid and sensitive method for the quantification of microgram quantities of protein utilizing the principle of protein-dye binding. Anal. Biochem. 72:248-254.

Bruemmer, J.H. 1986. Regulation of acetaldehyde and ethanol accumulation in citrus fruit. In: T.H. Parliament and R. Croteau (eds.). Biogeneration of aromas Amer. Chem. Soc. Symp. Ser. 317:276285.

Chen, A.R. and T.J. Chase. 1993. Alcohol dehydrogenase 2 and pyruvate decarboxylase induction in ripening and hypoxic tomato fruit. Plant Physiol. Biochem. 3:875-885.

Chervin, C. and J.K. Truett. 1999. Alcohol dehydrogenase expression and alcohol production during pear ripening. J. Amer. Soc. Hort. Sci. 124:71-75.

Cohen, E., Y. Shalom, and I. Rosenberger. 1990. Postharvest ethanol buildup and off-flavor in 'Murcott' tangerine fruits. J. Amer. Soc. Hort. Sci. 115:775-778.

Davis, P.L. 1971. Relation of ethanol content of citrus fruits to maturity and to storage conditions. Citrus Ind. 52:5$6,8,10$.

Davis, P.L., B. Roe, and J.H. Bruemmer. 1973. Biochemical changes in citrus fruits during controlled-atmosphere storage. J. Food Sci. 38:225-229.

Dolferus, R., G. Debruxelles, E.S. Dennis, and W.J. Peacock. 1994. Regulation of the Arabidopsis Adh gene by anaerobic and other environmental stresses. Ann. Bot. (Lond.) 74:301-308.

Fig. 8. Changes in rates of respiration, AA and ethanol evolution, and transcript levels of PDC and $\mathrm{ADH}$ in immature grapefruit and mandarin exposed to air (CK) or $\mathrm{N}_{2}$ atmosphere. Immature fruit were harvested (28 May 2005) and exposed to air or $\mathrm{N}_{2}$ atmosphere for $6 \mathrm{~h}$ and $24 \mathrm{~h}$ at $20^{\circ} \mathrm{C}$ in the dark. (A) Changes in rates of respiration, $\mathrm{AA}$, and ethanol evolution. Each value represents the average of 10 individual immature fruit at each time point \pm SE. Error bars not shown are smaller than the symbols used. (B) Changes in transcript levels of PDC and ADH in flavedo. Total RNA was extracted from flavedo. Blots were hybridized with specific probes. The ethidium bromide-stained rRNA bands are shown to indicate the equivalent RNA loading.
Eaks, I.L. 1970. Respiratory response, ethylene production, and response to ethylene of citrus fruit during ontogeny. Plant Physiol. 45:334-338.

Imahori, Y., M. Kota, H. Furukawa, Y. Ueda, and K. Chachin. 2000. Ethanolic fermentation enzymes, their products and transcription of alcohol dehydrogenase from bell pepper fruit held under various low oxygen atmospheres. J. Jpn. Soc. Hort. Sci. 69:266-272.

Jacob-Wilk, D., E.E. Goldschmidt, J. Riov, A. Sadka, and D. Holland. 1997. 
Induction of a Citrus gene highly homologous to plant and yeast thi genes involved in thiamine biosynthesis during natural and ethyleneinduced fruit maturation. Plant Mol. Biol. 35:661-666.

Kapri, R., E. Dahan, A. Sadka, U. Zehavi, and R. Goren. 2000. Cloning and characterization of PPi-phosphofructokinase from citrus fruit. Acta Hort. 535:113-118.

Katz, E., P.M. Lagunes, J. Riov, D. Weiss, and E.E. Goldschmidt. 2004. Molecular and physiological evidence suggests the existence of a system II-like pathway of ethylene production in non-climacteric Citrus fruit. Planta 219:243-252.

Ke, D. and A.A. Kader. 1990. Tolerance of 'Valencia' oranges to controlled atmospheres as determined by physiological responses and quality attributes. J. Amer. Soc. Hort. Sci. 115:779-783.

Ke, D., E. Yahia, B. Hess, L. Zhou, and A.A. Kader. 1995. Regulation of fermentative metabolism in avocado fruit under oxygen and carbon dioxide stresses. J. Amer. Soc. Hort. Sci. 120:481-490.

Keen, M. and S.G.S. Hatfield. 1981. The metabolism of alcohols by apple fruit tissue. J. Sci. Food Agr. 32:593-600.

Koch, K.E., Z. Ying, Y. Wu, and W.T. Avigne. 2000. Multiple paths of sugar-sensing and a sugar/oxygen overlap for genes of sucrose and ethanol metabolism. J. Expt. Bot. 51:417-427.

Lavilla, T., I. Recasens, and M.L. Lopez. 2001. Production of volatile aromatic compounds in Big Top nectarines and Royal Glory peaches during maturity. Acta Hort. 553:233-234.

Moyano, E., S. Encinas-Villarejo, J.A. Lopez-Raez, J. RedondoNevado, R. Blanco-Portales, M.L. Bellido, C. Sanz, J.L. Caballero, and J. Munoz-Blanco. 2004. Comparative study between two strawberry pyruvate decarboxylase genes along fruit development and ripening, post-harvest and stress conditions. Plant Sci. 166: 835-845.

Nanos, G.D. and A.A. Kader. 1993. Low $\mathrm{O}_{2}$-induced changes in $\mathrm{pH}$ and energy charge in pear fruit tissue. Postharvest Biol. Technol. 3:285-291.

Norman, S.M. and C.C. Craft. 1971. Production of ethanol, acetaldehyde, and methanol by intact oranges during and after nitrogen storage. J. Amer. Soc. Hort. Sci. 96:464-467.

Or, E., J. Baybik, A. Sadka, and A. Ogrodovitch. 2000. Fermentative metabolism in grape berries: Isolation and characterization of pyruvate decarboxylase cDNA and analysis of its expression throughout berry development. Plant Sci. 156:151-158.
Peng, H.P., C.S. Chan, M.C. Shih, and S.F. Yang. 2001. Signaling events in the hypoxic induction of alcohol dehydrogenase gene in arabidopsis. Plant Physiol. 126:742-749.

Pesis, E. 2005. The role of the anaerobic metabolites, acetaldehyde and ethanol, in fruit ripening, enhancement of fruit quality and fruit deterioration. Postharvest Biol. Technol. 37:1-19.

Pesis, E. and I. Avissar. 1989. The postharvest quality of orange fruits as affected by prestorage treatments with acetaldehyde vapors or anaerobic conditions. J. Hort. Sci. 64:107-113.

Porat, R., B. Weiss, L. Cohen, A. Daus, R. Goren, and S. Droby. 1999. Effects of ethylene and 1-methylcyclopropene on the postharvest qualities of 'Shamouti' oranges. Postharvest Biol. Technol. 15:155-163.

Ricard, B., I. Couee, P. Raymond, P.H. Saglio, V. Saintges, and A. Pradet. 1994. Plant metabolism under hypoxia and anoxia. Plant Physiol. Biochem. 32:1-10.

Robert, J.K.M., K. Chang, C. Webster, J. Callis, and V. Walbot. 1989. Dependence of ethanolic fermentation, cytoplasmic $\mathrm{pH}$ regulation, and viability on the activity of alcohol dehydrogenase in hypoxic maize root tips. Plant Physiol. 89:1275-1278.

Shellie, K.C. 2002. Ultra-low oxygen refrigerated storage of 'Rio Red' grapefruit: Fungistatic activity and fruit quality. Postharvest Biol. Technol. 19:179-186.

Shi, J.X., Z. Aharon, R. Goren, E.E. Goldschmidt, and R. Porat. 2005a. Short-term exposures to reduced $\mathrm{O}_{2}$ and elevated $\mathrm{CO}_{2}$ atmospheres differently affect the respiratory characteristics of grapefruit and mandarin. Acta Hort. (in press).

Shi, J.X., R. Porat, R. Goren, and E.E. Goldschmidt. 2005b. Physiological responses of 'Murcott' mandarins and 'Star Ruby' grapefruit to anaerobic stress conditions and their relation to fruit taste, quality and emission of off-flavor volatiles. Postharvest Biol. Technol. 38:99-105.

Tadege, M. and C. Kuhlemeier. 1997. Aerobic fermentation during tobacco pollen development. Plant Mol. Biol. 35:343-354.

Tesniere, C., M. Pradal, A. El-Kereamy, L. Torregrosa, P. Chatelet, J.P. Roustan, and C. Chervin. 2004. Involvement of ethylene signalling in a non-climacteric fruit: New elements regarding the regulation of $A D H$ expression in grapevine. J. Expt. Bot. 55:2235-2240.

Tesniere, C. and C. Verries. 2000. Molecular cloning and expression of cDNAs encoding alcohol dehydrogenase from Vitis vinifera L. during berry development. Plant Sci. 157:77-88. 